\title{
Pengaruh Produk, Harga, Bahan Baku Bagi Penjualan di PT. Hon Chuan Indonesia Periode 2015-2019
}

\author{
Yeni $^{1)}$, Hartelina $^{2)}$, Didit Supriadi $^{3)}$, DJ Suyaman ${ }^{4)}$ \\ Fakultas Ekonomi Universitas Singaperbangsa Karawang \\ Email : jajang@fe.unsika.ac.id
}

\begin{abstract}
ABSTRAK
Perkembangan industri plastik di Indonesia yang tinggi memiliki potensi lonjakan akan kebutuhan bahan baku biji plastik di Indonesia, dimana sumber alam biji plastik pun saat ini terbatas dan dibatasi. Hal tersebut memberikan dampak atas peningkatan impor biji plastik terutama bagi bisnis kemasan plastik khususnya sektor makanan dan minuman yang menggunakan bahan baku tersebut. Ketatnya persaingan dan tantangan akan batasan penggunaan bahan baku plastik, memerlukan adanya perhatian akan produk, harga, bahan baku, dan dampaknya pada penjualan. Tujuan penelitian ini adalah untuk memberikan gambaran produk, harga, bahan baku dan penjualan, menganalisis nilai korelasi dan pengaruh antar variabel tersebut. Penelitian dilakukan dengan metode penelitian kuantitatif dengan pendekatan deskriptif dan penelitian survey yang dilakukan di PT. Hon Chuan Indonesia dengan sampel sebanyak 118 perwakilan berdasarkan data pelanggan. Berdasarkan hasil penelitian secara deskriptif bahwa produk dan harga berada pada kategori setuju. Dan secara verifikatif memiliki 1) korelasi dengan rentang cukup kuat dan kuat antar produk dan harga, 2) berpengaruh parsial signifikan positif antara produk, harga, dan bahan baku 3) berpengaruh simultan antara produk, harga, dan bahan baku 4) berpengaruh antara bahan baku dan penjualan.
\end{abstract}

Kata kunci : Bahan baku, Penjualan, Produk, Harga, Kemasan plastik

\begin{abstract}
The increasing of plastic industry growth in Indonesia have bump-up potential of plastic pellets requirement as well, which the nature source of plastic pellets itself restricted and limited. Those will impact to plastic pellets import high demand especially for food and beverages area who use them. Strict competition and challenges to the restriction of plastic raw material usage need attention on product, price, raw material, and impact to the sales. The purpose of this study was to describe of product, price, raw material, and impact to sales, analyze the correlation value and the effect among them. This study was conducted use quantitative research method with descriptive approach and survey method. This study conducted in PT. Hon Chuan Indonesia with 118 respondents as representative from their customer data. Based on research result marketing strategy, product, price, raw material, and sales was in approve category descriptively. And it has 1) a fairly strong and strong correlation range between product and price, 2) significant positive partially effect between product, price, and raw material 3) simultaneously effect between product, price, and raw material 4) influence between raw material and sales.
\end{abstract}

Keywords: Raw material, Sales, Product, Price, Plastic Packaging

\section{PENDAHULUAN}

Industri plastik memiliki potensi besar untuk dikembangkan di Indonesia karena tingkat konsumsi terhadap kebutuhan komoditas tersebut cukup tinggi. Hal tersebut senada dengan apa yang pernah dikemukakan oleh Sekjen Kementerian Perindustrian, Haris Munandar mewakili Menteri Perindustrian pada Pembukaan Pameran Produk
Industri Plastik dan Karet Hilir di Jakarta, 3 Oktober 2017 (dikutip dari artikel Kemenperin). Beliau menyatakan bahwa "Pengembangan industri plastik dan karet di dalam negeri masih prospektif, mengingat industri ini merupakan sektor vital dengan ruang lingkup mulai dari hulu, antara hingga hilir, yang selalu dibutuhkan oleh industri lain dan memiliki variasi produk yang sangat luas." 
Dikutip dari laman trubus news, Direktur Industri Kimia Hilir dan Farmasi Kementerian Perindustrian (Kemenperin), Taufiek Bawazier dalam keterangan tertulis yang diterima di Jakarta, Senin (26/8/2019), menyatakan bahwa bahan baku ini diimpor karena kebutuhan bahan baku plastik masih sangat tinggi. Beliau juga menyatakan bahwa secara kebutuhan nasional, Indonesia memerlukan bahan baku plastik untuk produksi sebanyak 7.2 juta ton per tahun. Dimana saat ini persediaan bahan baku plastik baru sekitar 2.3 juta ton.

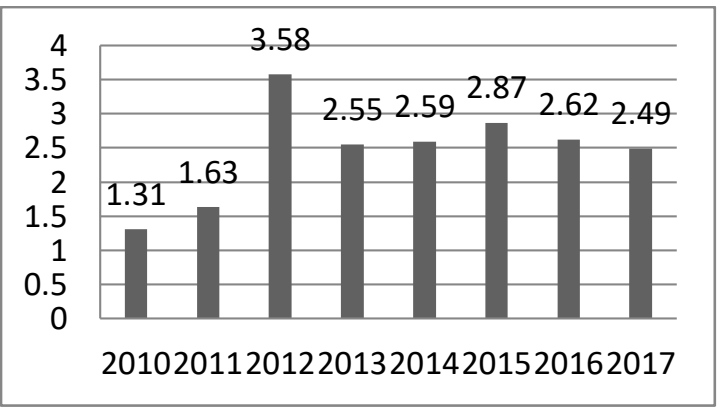

Sumber: globalplanet.news

\section{Gambar 1. Impor Bahan Baku Plastik Indonesia $2010-2017$}

Mengikuti era yang semakin canggih dan menghadapi revolusi industri 4.0, kompetitif persaingan yang ada memaksa pelaku bisnis untuk terus memperhatikan produk, harga, lokasi atau distribusi, promosi, sumber daya manusia, proses, dan tampilan fisik menjadi hal yang dirasa mumpuni dalam menangani hal tersebut. Baik memperhatikan secara internal (perusahaan sendiri) bahkan harus mampu memperhatikan yang dimiliki oleh lingkungan sekitar atau eksternal (pesaing). Tidak sedikit perusahaan yang menerapkan produknya dalam berbagai inovasi dan kreativitas dengan tujuan tingginya nilai penjualan.

Produk dan harga diwajibkan memiliki pangsa pasar yang jelas dan bersaing. Sangatlah dibutuhkan kemampuan harga yang kompetitif dan produk yg sebanding. Menetapkan harga yang kompetitif menjadi salah satu unsur yang harus diputuskan dengan sangat bijak oleh tingkat manajemen perusahaan. Harga yang ditawarkan juga harus mampu dijangkau dan diharapkan oleh konsumen sehingga mampu menarik mereka untuk memperlihatkan kebutuhannya akan produk yang kita ciptakan.

PT. Hon Chuan Indonesia sebagai salah satu pelaku di industri minuman dan kemasan plastik memiliki misi untuk mencapai pertumbuhan yang berkelanjutan. Untuk mengetahui apakah misi tersebut sudah terlaksana, kita bisa lihat melalui penjualan yang diperoleh dalam kurun waktu sembilan tahun terakhir sebagai berikut :
Tabel 1. Penjualan PT. Hon Chuan Indonesia Periode 2015 - 2019

\begin{tabular}{cccc}
\hline Tahun & $\begin{array}{c}\text { Target Penjualan } \\
\text { (Rp dalam Milyar) }\end{array}$ & $\begin{array}{c}\text { Hasil Penjualan } \\
\text { (Rp dalam Milyar) }\end{array}$ & $\begin{array}{c}\text { Rasio Penjualan } \\
(\%)\end{array}$ \\
\hline 2015 & 386,1 & 201,1 & 52.09 \\
2016 & 525,2 & 264,8 & 50.42 \\
2017 & 439 & 395 & 89.97 \\
2018 & 498 & 553,6 & 111.17 \\
2019 & 579,5 & 921,9 & 159.08 \\
\hline
\end{tabular}

Sumber: Data Penjualan PT. Hon Chuan Indonesia 2015-2019

Data penjualan memperlihatkan fluktuasi naik dan turun penjualan yang sangat tidak stabil, baik dilihat dari target dan hasil penjualanna. Dari data tersebut, perlu dianalisa lebih dalam jika produk yang dimiliki dan harga yang digunakan yang menjadi alasan dari hasil tersebut. Selain itu, apakah bahan baku yang terbatas dan dibatasi ini memiliki pengaruh yang sama pada hasil penjualannya.

\section{TINJAUAN PUSTAKA}

Menurut American Marketing Association dalam Alma (2013: 3), pemasaran dinyatakan sebagai proses perencanaan dan pelaksanaan konsepsi penentuan harga, promosi dan pendistribusian barang, jasa dan ide yang dapat memuaskan konsumen dan tujuan perusahaan.

Menurut Kotler dan Armstrong $(2018,272)$ terkait pengertian produk adalah apapun yang dapat ditawarkan untuk menarik perhatian pasar, dapat diterima, dapat digunakan atau dapat dikonsumsi yang mungkin memberikan kepuasan yang diinginkan atau dibutuhkan. Oleh karena itu, alangkah baiknya bagi setiap perusahaan untuk terus melakukan inovasi terhadap produknya seiring dengan perkembangan zaman.

H. Abdul Manap (2016, 289) menyatakan harga adalah nilai suatu barang yang dinyatakan dengan uang. Hal tersebut sejalan dengan yang dikemukakan oleh Kotler dan Armstrong (2018, 197), harga adalah sejumlah uang yang harus dibayar konsumen untuk memperoleh suatu produk. Dapat disimpulkan bahwa harga adalah pertukaran antara produk dengan uang. Harga juga mempunyai banyak bentuk dan banyak fungsi. Harga juga mengkomunikasikan positioning nilai yang dimaksudkan dari produk atau merek perusahaan ke pasar. Harga yang dirancang dan dipasarkan dengan baik dapat dijual dengan tinggi dan menghasilkan laba yang besar.

Pengertian bahan baku adalah, barang-barang yang akan menjadi bagian dari produk jadi yang dengan mudah dapat diikuti biayanya (Singgih Wibowo, 2014, 12). Menurut Sujarweni (2015:27-28), bahan 
baku sendiri mempunyai definisi bahan-bahan yang merupakan komponen utama yang membentuk keseluruhan dari produk jadi. Dari semua pengertian di atas, bahan baku merupakan semua bahan atau barang yang digunakan oleh perusahaan yang diikuti dengan biaya yang akan membentuk produk jadi. Sehingga bahan baku menjadi perhatian utama yang perlu dilakukan persediaan untuk memastikan kegiatan utama perusahaan berjalan dengan lancar.

Putu Agus Semara Jaya (2015, 3), penjualan adalah hasil yang dicapai oleh perusahaan atau instansi dari waktu ke waktu pada umunya tetap, tetapi selalu turun naik. Kemungkinan turun naiknya hasil penjualan terjadi secara teratur sehingga perusahaan dapat memiliki pedoman yang tetap didalam pembuatan peramalan. Menurut Francis Tantri dan Thamrin (2016:3) penjualan adalah bagian dari promosi dan promosi adalah salah satu bagian dari keseluruhan sistem pemasaran. Dari pengertian tersebut, penjualan merupakan bagian dari kegiatan pemasaran yang berhasil dicapai dalam jumlah atau hasil yang diharapkan dalam jangka waktu tertentu.

\section{METODE PENELITIAN}

Objek pada penelitian ini adalah PT. Hon Chuan Indonesia pada periode 2015-2019. Populasi penelitian adalah seluruh pelanggan dari objek penelitian selama periode tersebut sebanyak 118 perwakilan berdasarkan data perusahaan. Pada penelitian ini, peneliti menggunakan sampling jenuh sehingga jumlah sampel pada penelitian ini adalah 118 perusahaan tersebut.

Variabel yang digunakan dalam penelitian ini adalah variabel independen dan variabel dependen. Operasional variabel yang akan digunakan terdiri dari 1) produk, 2) harga 3) bahan baku sebagai variabel independen, dan 4) penjualan sebagai variabel dependen-nya.

Dalam penelitian ini, teknik pengumpulan data yang digunakan adalah dengan melakukan wawancara dan menyebarkan kuesioner dengan menggunakan instrumen berikut :

\section{Tabel 2. Instrumen Penilaian Kuesioner}

\begin{tabular}{lc}
\hline \multicolumn{1}{c}{ Jawaban Responden } & Skor Penilaian \\
\hline Sangat Setuju (SS) & 5 \\
Setuju (S) & 4 \\
Cukup (C) & 3 \\
Tidak Setuju (TS) & 2 \\
Sangat Tidak Setuju (SST) & 1 \\
\hline
\end{tabular}

Uji keabsahan data pada penelitian ini dengan menggunakan uji validitas, reliabilitas, dan normalitas. Untuk mencari validitas sebuah item, kita mengkorelasikan skor item dengan total itemitem tersebut. Jika koefisien antara item degan total item sama atau diatas 0,3 maka item tersebut dinyatakan valid, tetapi jika nilai korelasinya dibawah 0,3 maka item tersebut dinyatakan tidak valid. Dalam mencari nilai korelasi penulis menggunakan rumus pearson Product Moment, dengan rumus sebagai berikut :

$r=\frac{n\left(\sum X Y\right)-\left(\sum X\right) \cdot\left(\sum Y\right)}{\sqrt{\left\{n \cdot \sum X^{2}-\left(\sum X\right)^{2}\right\}} \cdot \sqrt{\left\{n \cdot \sum Y^{2}-\left(\sum Y\right)^{2}\right\}}} \rightarrow(1)$

Dimana : r XY=Korelasi XY

a. $\mathrm{n}=$ Jumlah Sampel

b. $\quad \mathrm{X}=$ Skor Per Item

c. $\mathrm{Y}=$ Total Per Skor

Sumber : Riduwan (2012:62)

Untuk uji reliabilitas digunakan metode split half, hasilnya bisa dilihat dari nilai Correlation Between Forms. Hasil penelitian reliabel terjadi apabila terdapat kesamaan data dalam waktu yang berbeda. Metode yang digunakan adalah Split Half, dimana instrument dibagi menjadi dua kelompok.

$r A B=\frac{\left(n \sum A B\right)-\left(A \sum B\right)}{\sqrt{\left\{n\left(\sum A^{2}\right)-\left(\sum A\right)^{2}\right\}\left\{n\left(\sum B\right)^{2}-\left(\sum B\right)^{2}\right\}}} \rightarrow(2)$

Keterangan:

$\mathrm{rAB}=$ Korelasi Pearson Product Moment

$\sum \mathrm{A}=$ Jumlah total skor belahan ganjil

$\sum \mathrm{B}=$ Jumlah total skor belahan genap

$\sum \mathrm{A} 2=$ Jumlah kuadrat skor belahan ganjil

$\sum \mathrm{B} 2=$ Jumlah kuadrat skor belahan genap

$\sum \mathrm{AB}=$ Jumlah perkalian skor jawaban belahan ganjil dan genap

Apabila korelasi 0,7 atau lebih maka dikatakan item tersebut memberikan tingkat reliabel yang cukup tinggi, namun sebaliknya apabila nilai korelasi dibawah 0,7 maka dikatakan item tersebut kurang reliabel. Kemudian koefisien korelasinya dimasukan kedalam rumus Spearman Brown:

$r=\frac{2 r b}{1+r b} \rightarrow(3)$

Keterangan:

$\mathrm{r} \quad=$ Koefisien korelasi

$\mathrm{rb}=$ Korelasi product moment antara belahan pertama dan kedua batas reliabilitas minimal 0,7

Setelah di dapat nilai reliabilitas (rhitung) maka nilai tersebut dibandingkan dengan rtabel yang sesuai dengan jumlah responden dan taraf nyata dengan ketentuan sebagai berikut:

Bila rhitung $\geq$ rtabel: Instrument tersebut dikatakan reliabel

Bila rhitung $\leq$ rtabel : Instrument tersebut dikatakan tidak reliabel

Uji Normalitas yang digunakan adalah Kolmogorov Smirnov yaitu dengan membandingkan distribusi 
data (yang akan di uji normalitasnnya) dengan distribusi normal baku. Distribusi normal baku adalah data yang telah di transformasikan ke dalam bentuk Z-Score dan di asumsikan normal. Penerapan uji Kolmogorov Smirnov adalah bahwa jika signifikansi di bawah 0,05 berarti data yang akan di uji mempunyai perbedaan yang signifikan dengan data normal baku, berarti data tersebut tidak normal.

$\mathrm{p}<0,05$ (distribusi data tidak normal)

$p \geq 0,05$ (distrbusi data normal)

Rancangan analisis yang digunakan pada penelitian ini adalah rancangan analisis deskriptif, verifikatif, uji t (uji parsial), uji f (uji simultan), dan uji hipotesis. Metode yang digunakan dalam analisis deskriptif ini yaitu dengan menggunakan rentang skala. Rumus rentang skalanya adalah :

$R S=\frac{n(m-1)}{M} \quad \rightarrow(4)$

Sumber: Sugiyono, 2014

Dimana :

$$
\begin{array}{ll}
\mathrm{RS} & =\text { Rentang Skala } \\
\mathrm{n} & =\text { Jumlah sampel } \\
\mathrm{m} & =\text { Bobot pendapat tertinggi }
\end{array}
$$

Sementara untuk rancangan analisis verifikatifnya, penelitian ini menggunakan analisis teknik jalur (path analysis).

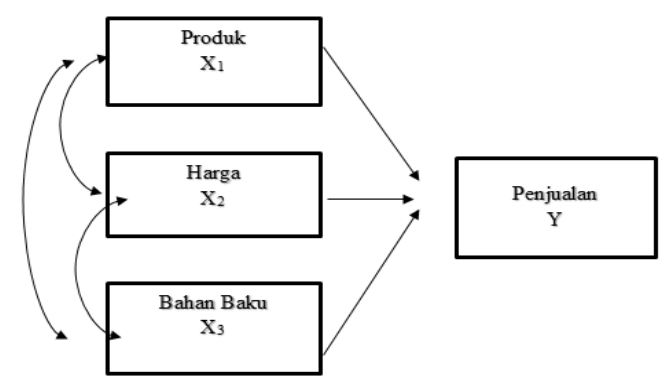

Gambar 2. Analisa Jalur

Lalu uji t (uji parsial) yang digunakan memiliki kriteria pengujian dengan tingkat signifikansi $(\alpha)=$ 0,05 ditentukan sebagai berikut:

1. Jika t hitung > t tabel, Ha diterima dan Ho ditolak, berarti terdapat pengaruh yang signifikan antara masing- masing variabel independen terhadap variabel dependen.

2. Jika t hitung < t tabel, Ho diterima dan Ha ditolak, berarti tidak terdapat pengaruh yang signifikan antara masing - masing variabel independen terhadap variabel dependen.

Uji f (uji simultan) yang digunakan memiliki kriteria:

1. Jika $\mathrm{F}$ hitung > F tabel, Ha diterima dan Ho ditolak, berarti terdapat pengaruh yang positif secara (simultan) bersama-sama antara variabel independen terhadap variabel dependen.

2. Jika $\mathrm{F}$ hitung $<\mathrm{F}$ tabel, Ho diterima dan $\mathrm{Ha}$ ditolak, berarti tidak terdapat pengaruh yang positif secara (simultan) bersama-sama antara variabel independen terhadap variabel dependen.

Dan yang terakhir adalah uji hipotesis pada penelitian ini ditentukan sebagai berikut:

1. Korelasi Antara Produk dengan Harga, Harga dengan Bahan Baku, Produk dengan Bahan Baku (uji t)

$\mathrm{H}_{0}: \mathrm{rX}_{1} \mathrm{X}_{2}=0:$ Tidak terdapat kolerasi

$\mathrm{H}_{1}: \mathrm{rX}_{1} \mathrm{X}_{2} \neq 0$ : Terdapat kolerasi

2. Pengaruh Parsial Produk, Harga, Bahan Baku terhadap Penjualan (uji t)

$\mathrm{H}_{0}: \operatorname{pyx}_{1}, \operatorname{pyx}_{2}=0:$ Tidak terdapat pengaruh

$\mathrm{H}_{1}$ : $\operatorname{pyx}_{1}, \operatorname{pyx}_{2} \neq 0$ : Terdapat pengaruh

3. Pengaruh Simultan Produk, Harga, Bahan Baku terhadap Penjualan (uji f)

$\mathrm{H}_{0}$ : $\operatorname{pyx}_{1}, \operatorname{pyx}_{2}, \operatorname{pyx}_{1} \mathrm{x}_{2}=0$ : Tidak terdapat pengaruh secara bersama-sama

$\mathrm{H}_{1}$ : $\operatorname{pyx}_{1}, \operatorname{pyx}_{2}, \operatorname{pyx}_{1} \times 2 \neq 0$ : Terdapat pengaruh secara bersama-sama

\section{HASIL DAN PEMBAHASAN}

Hasil penelitian ini bertujuan untuk mengungkapkan sasaran yang ingin dicapai dalam penelitian pengaruh produk, harga, bahan baku terhadap penjualan di PT. Hon Chuan Indonesia periode 2015-2019. Dalam pengujian keabsahan data yang diuji adalah data hasil penyebaran kuesioner.

Untuk menentukan valid atau tidaknya instrumen tersebut adalah dengan membandingkan hasil perhitungan korelasi dengan tabel harga kritis dan $r$ product moment pada taraf kepercayaan $95 \%$ atau signifikan 5\%. Berdasarkan rujukan para $\mathrm{r}$ tabel dengan jumlah sampel-2 = 118 dengan signifikansi 0.05 didapatlah persyaratan minimum agar dapat dianggap valid apabila $\mathrm{r}$ kritis $=0,179$. Berikut hasilnya:

Tabel 3. Hasil Uji Validitas

\begin{tabular}{clccc}
\hline No & Variabel & $\begin{array}{c}\text { R hitung } \\
\text { min }\end{array}$ & $\begin{array}{c}\text { R kritis } \\
\text { min }\end{array}$ & Ket. \\
\hline 1 & Produk & 0,285 & $\geq 0,179$ & Valid \\
2 & Harga & 0,507 & $\geq 0,179$ & Valid \\
3 & Bahan Baku & 0,302 & $\geq 0,179$ & Valid \\
4 & Penjualan & 0,466 & $\geq 0,179$ & Valid \\
\hline
\end{tabular}

Sumber: Data Hasil Pengolahan SPSS Dari Jawaban Kuesioner, 2020 
Sujarweni mengungkapkan uji reliabilitas merupakan ukuran suatu kestabilan dan konsistensi responden dalam menjawab hal yang berkaitan dengan konstruk-konstruk pertanyaan yang merupakan dimensi suatu variabel dan disusun dalam suatu bentuk kuesioner (2018: 134). Dimana variabel dinyatakan reliabel jika memiliki nilai Alpha $(\alpha)$ lebih besar dari 0,60. Dan pada penelitian ini, semua variabel dinyatakan reliabel sebagai berikut :

Tabel 4. Hasil Uji Reliabilitas

\begin{tabular}{ccccc}
\hline No & \multicolumn{1}{c}{ Variabel } & R litung & R kritis & Ket. \\
\hline 1 & Produk & 0,724 & $>0,60$ & Reliabel \\
2 & Harga & 0,804 & $>0,60$ & Reliabel \\
3 & Bahan Baku & 0,682 & $>0,60$ & Reliabel \\
4 & Penjualan & 0,689 & $>0,60$ & Reliabel \\
\hline
\end{tabular}

Sumber: Data Hasil Pengolahan SPSS Dari Jawaban Kuesioner, 2020

Uji normalitas digunakan untuk mengetahui apakah suatu data mengikuti sebaran normal atau tidak dengan menggunakan metode KolmogorovSmirnov. Dengan ketentuan apabila variabel memiliki nilai $\alpha$ hitung lebih besar dari 0,05 maka variabel tersebut mengikuti distribusi normal.

a. Jika signifikansi > 0,05 maka, data tersebut berdistribusi normal

b. Jika signifikansi $<0,05$ maka, data tersebut tidak berdistribusi normal

Hal tersebut seperti ditunjukkan pada tabel berikut ini :

Tabel 5. Hasil Uji Normalitas

\begin{tabular}{ccccc}
\hline No & Variabel & R lituıg & R kritis & Ket. \\
\hline 1 & Produk & 0,200 & $>0,05$ & Berdistribusi Nomal \\
2 & Harga & 0,125 & $>0,05$ & Berdistribusi Normal \\
3 & Bahan Baku & 0,106 & $>0,05$ & Berdistribusi Normal \\
4 & Penjualan & 0,200 & $>0,05$ & Berdistribusi Normal \\
\hline
\end{tabular}

Sumber: Data Hasil Pengolahan SPSS Dari Jawaban Kuesioner, 2020

Berdasarkan penjelasan tersebut dapat dipastikan data seluruh variabel berdistribusi normal karena nilai Kolmogorov-Smirnov > 0,05.
Tabel 6. Nilai Kolmogorov-Smirnow

\begin{tabular}{|c|c|c|c|c|c|}
\hline \multicolumn{6}{|c|}{ One-Sample Kolmogorov-Smirnov Test } \\
\hline & & $\begin{array}{c}\text { PRODUK } \\
(\mathrm{X} 1)\end{array}$ & $\begin{array}{c}\text { HARGA } \\
(\mathrm{X} 2)\end{array}$ & $\begin{array}{c}\text { BAHAN } \\
\text { BAKU }(\mathrm{X} 3)\end{array}$ & $\begin{array}{c}\text { PENJUALA } \\
\mathrm{N}(\mathrm{Y})\end{array}$ \\
\hline $\mathrm{N}$ & & 118 & 118 & 118 & 118 \\
\hline \multirow[t]{2}{*}{ Normal Parameters ${ }^{\mathrm{a}, \mathrm{b}}$} & Mean & 36.2881 & 22.7119 & 19.2712 & 14.8644 \\
\hline & $\begin{array}{l}\text { Std. } \\
\text { Deviation }\end{array}$ & 3.43213 & 3.43959 & 2.61377 & 2.38197 \\
\hline Most Extreme & Absolute & .089 & .083 & .094 & .099 \\
\hline \multirow[t]{2}{*}{ Differences } & Positive & .089 & .083 & .094 & .087 \\
\hline & Negative & -.082 & -.079 & -.076 & -.099 \\
\hline Test Statistic & & .082 & .089 & .076 & .099 \\
\hline Asymp. Sig. (2-tailed) & & $.200^{\circ}$ & $.125^{\mathrm{c}}$ & $.106^{\circ}$ & $.200^{\circ}$ \\
\hline
\end{tabular}

a. Test distribution is Normal

b. Calculated from data

c. Lilliefors Significance Correction

Sumber: Data Hasil Pengolahan SPSS dari Jawaban

Kuesioner 2020

Tabel 7. Uji Analisis Linier Berganda (Uji t parsial) Coefficients $^{\mathrm{a}}$

\begin{tabular}{|c|c|c|c|c|c|}
\hline \multirow[t]{2}{*}{ Model } & \multicolumn{2}{|c|}{$\begin{array}{l}\text { Unstandardized } \\
\text { Coefficients }\end{array}$} & \multirow{2}{*}{$\begin{array}{l}\text { Standardized } \\
\text { Coefficients } \\
\text { Beta }\end{array}$} & \multirow[t]{2}{*}{$\mathrm{t}$} & \multirow[t]{2}{*}{ Sig. } \\
\hline & B & Std. Error & & & \\
\hline (Constant) & -3.261 & 1.346 & & -2.422 & .017 \\
\hline PRODUK (X1) & .226 & .049 & .326 & 4.652 & .000 \\
\hline HARGA (X2) & .285 & .079 & .412 & 3.603 & .000 \\
\hline BAHAN BAKU $(X 3)$ & .178 & .092 & .195 & 1.945 & .054 \\
\hline
\end{tabular}

a. Dependent Variable: PENJUALAN (Y)

Sumber: Data Hasil Pengolahan SPSS Dari Jawaban

Kuesioner,2020

Tabel 8. $X_{1}, X_{2}, X_{3}$ terhadap $Y$

\begin{tabular}{cccccc}
\hline Structural & Sig. & A & $\mathbf{t}_{\text {hitug }}$ & $\mathbf{t}_{\text {kritis }}$ & Keterangan \\
\hline Pyx 1 & 0,000 & 0,05 & 4,652 & 1,657 & Berpengaruh parsial \\
Pyx 2 & 0,000 & 0,05 & 3.603 & 1,657 & Berpengaruh parsial \\
Pyx 3 & 0,000 & 0,05 & 1,945 & 1,657 & Berpengaruh parsial \\
\hline
\end{tabular}

Sumber: Data Hasil Pengolahan SPSS Dari Jawaban Kuesioner,2020

Tabel 9. Uji Simultan (Uji f)

\begin{tabular}{rlrrrrr}
\multicolumn{7}{c}{ ANOVA $^{\text {a }}$} \\
\hline \multirow{2}{*}{ Model } & \multicolumn{1}{c}{$\begin{array}{l}\text { Sum of } \\
\text { Squares }\end{array}$} & df & Mean Square & F & Sig. \\
\hline 1 & Regression & 476.550 & 3 & 158.850 & 96.694 & $.000^{b}$ \\
& Residual & 187.280 & 114 & 1.643 & & \\
Total & 663.831 & 117 & & & \\
\hline
\end{tabular}

a. Dependent Variable: PENJUALAN (Y)

b. Predictors: (Constant), BAHAN BAKU (X3), PRODUK (X1), HARGA (X2) 
Tabel 10. Uji f Produk $\left(X_{1}\right)$, Harga $\left(X_{2}\right)$ dan Bahan Baku $\left(X_{3}\right)$ terhadap Penjualan $(Y)$ secara simultan

\begin{tabular}{ccccc}
\hline Structural & $\mathbf{A}$ & $\mathbf{f}_{\text {hitung }}$ & $\mathbf{f}_{\text {kritis }}$ & Keterangan \\
\hline $\mathrm{Pyx}_{1} \mathrm{x}_{2} \mathrm{X}_{3}$ & 0,05 & 96,69 & 2,29 & Berpengaruh simultan \\
\hline
\end{tabular}

Sumber: Data Hasil Pengolahan SPSS Dari Jawaban Kuesioner,2020

Tabel 11. Uji Korelasi Antar Variabel Bebas Correlations

\begin{tabular}{llccc}
\hline & & $\begin{array}{c}\text { PRODUK } \\
(\mathbf{X} 1)\end{array}$ & $\begin{array}{c}\text { HARGA } \\
(\mathbf{X} 2)\end{array}$ & $\begin{array}{c}\text { BAHAN BAKU } \\
(\mathbf{X} 3)\end{array}$ \\
\hline \multirow{3}{*}{ PRODUK (X1) } & $\begin{array}{l}\text { Pearson } \\
\text { Correlation }\end{array}$ & 1 & $.703^{* *}$ & $.587^{* *}$ \\
\cline { 2 - 5 } & Sig. (2-tailed) & & .000 & .000 \\
\cline { 2 - 5 } $\mathrm{N}$ & 118 & 118 & 118 \\
\hline \multirow{3}{*}{ HARGA (X2) } & $\begin{array}{l}\text { Pearson } \\
\text { Correlation }\end{array}$ & $.703^{* *}$ & 1 & $.868^{* *}$ \\
\cline { 2 - 5 } & Sig. (2-tailed) & .000 & & .000 \\
\cline { 2 - 5 } & $\mathrm{N}$ & 118 & 118 & 118 \\
\hline \multirow{2}{*}{$\begin{array}{l}\text { BAHAN BAKU } \\
\text { (X3) }\end{array}$} & $\begin{array}{l}\text { Pearson } \\
\text { Correlation }\end{array}$ & $.587^{* *}$ & $.868^{* *}$ & 1 \\
\cline { 2 - 5 } & Sig. (2-tailed) & .000 & .000 & 118 \\
\cline { 2 - 5 } & $\mathrm{N}$ & 118 & 118 & 118 \\
\hline
\end{tabular}

**. Correlation is significant at the 0.01 level (2-tailed).

Tabel 12. Korelasi Antar Variabel Bebas

\begin{tabular}{clcc}
\hline No & \multicolumn{1}{c}{ Variabel } & $\begin{array}{c}\text { Nilai } \\
\text { korelasi }\end{array}$ & Keterangan \\
\hline 1 & Produk $\left(\mathrm{X}_{1}\right)$ dengan Harga $\left(\mathrm{X}_{2}\right)$ & 0,703 & Kuat \\
2 & Harga $\left(\mathrm{X}_{2}\right)$ dengan Bahan Baku $\left(\mathrm{X}_{3}\right)$ & 0,868 & Sangat Kuat \\
3 & Produk $\left(\mathrm{X}_{1}\right)$ dengan Bahan Baku $\left(\mathrm{X}_{3}\right)$ & 0,587 & Cukup Kuat \\
\hline
\end{tabular}

Tabel 13. Uji Koefisien Determinasi

\begin{tabular}{llrrr}
\hline Model & R & R Square & $\begin{array}{c}\text { Adjusted R } \\
\text { Square }\end{array}$ & $\begin{array}{r}\text { Std. Error of } \\
\text { the Estimate }\end{array}$ \\
\hline 1 & $.847^{\mathrm{a}}$ & .718 & .710 & 1.28172 \\
\hline
\end{tabular}

a. Predictors: (Constant), BAHAN BAKU (X3),

PRODUK (X1), HARGA (X2)

Data menunjukan bahwa koefisien determinasi (r2) adalah 0,718 berarti $71,8 \%$ variabel Penjualan (Y) bisa diterangkan oleh variabel Produk, Harga dan Bahan Baku yang memiliki konstribusi terhadap Penjualan sebesar $71,8 \%$ sedangkan sisanya 28,2\% merupakan konstribusi variabel lain yang tidak diteliti $(\varepsilon)$

Kemudian merujuk pada hasil pengolahan data dengan bantuan software SPSS 22.0 didapatkan nilai koefisien jalur untuk setiap pengaruh variabel Produk, Harga dan Bahan Baku terhadap Penjualan. Hasil analisis tersebut dapat dilihat pada gambar berikut ini :

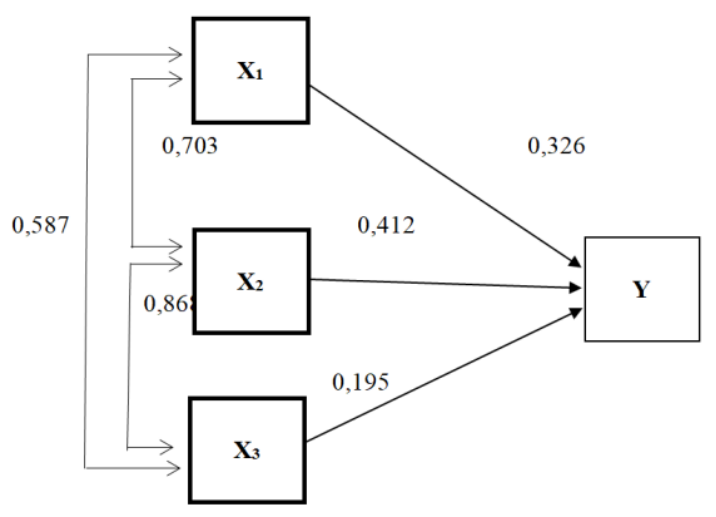

Gambar 3. Koefisien Jalur

\section{Variabel $X_{1}, X_{2}$ dan $X_{3}$ terhadap $Y$}

Berdasarkan gambar 3 di atas terlihat bahwa besaran derajat asosiatif atau koefisien jalur variabel Harga $(0,412)$ lebih tinggi dibandingkan kedua variabel lain yaitu Produk $(0,326)$ dan Bahan Baku $(0,195)$, artinya Harga lebih berpengaruh terhadap Penjualan. Adapun persamaan jalurnya sebagai berikut :

$Y=\left(0,326 X_{1}\right)+0,412 X_{2}+\left(0,195 X_{3}\right) \rightarrow(5)$

Dimana :

$\mathrm{X}_{1}:$ Produk

$\mathrm{X}_{2}$ : Harga

$\mathrm{X}_{3}$ : Bahan Baku

$\mathrm{Y}$ : Penjualan

Secara verifikatif dari penelitian 4 (lima) variabel ini dapat diuraikan sebagai berikut :

1. Korelasi Produk Dengan Harga, diperoleh besaran nilai koefisien korelasi diantara keduanya sebesar 0,703. Dengan demikian Produk dengan Harga memiliki tingkat korelasi yang kuat dan searah nilainya positif dikarenakan berada di interval koefisien nilai 0,60 sampai 0,799 (sugiyono, 2013:184). Dan berdasarkan hasil uji hipotesis, diperoleh $t_{\text {tabel }}=1,657$. Dengan demikian diketahui $t_{\text {hitung }}(4,652)>t_{\text {tabel }}(1,657)$, maka dapat dinyatakan bahwa $\mathrm{H}_{\mathrm{o}}$ ditolak, artinya ada hubungan yang signifikan antara Produk dengan Harga.

2. Korelasi Harga Dengan Bahan Baku, diperoleh besaran nilai koefisien korelasi diantara keduanya sebesar 0,868. Dengan demikian Harga dengan Bahan Baku memiliki tingkat korelasi yang sangat kuat dan searah nilainya positif dikarenakan berada di interval koefisien nilai 0,60 sampai 0,799 (sugiyono, 2013:184). Dan berdasarkan hasil uji hipotesis, diperoleh $t_{\text {tabel }}=1,657$. Dengan demikian diketahui $t_{\text {hitung }}(3.603)>t_{\text {tabel }}(1,657)$, maka dapat dinyatakan bahwa $\mathrm{H}_{\mathrm{o}}$ ditolak, artinya ada hubungan yang signifikan antara Harga dengan Bahan Baku. 
3. Korelasi Produk Dengan Bahan Baku, diperoleh besaran nilai koefisien korelasi diantara keduanya sebesar 0,587. Dengan demikian Produk dengan Bahan Baku memiliki tingkat korelasi yang cukup kuat dan searah nilainya positif dikarenakan berada di interval koefisien nilai 0,40 sampai 0,599 (sugiyono, 2013:184). Dan berdasarkan hasil uji hipotesis, diperoleh $t_{\text {tabel }}=1,657$. Dengan demikian diketahui $t_{\text {hitung }}(1,945)>t_{\text {tabel }}(1,657)$, maka dapat dinyatakan bahwa $\mathrm{H}_{\mathrm{o}}$ ditolak, artinya ada hubungan yang signifikan antara Produk dengan Bahan Baku.

4. Pengaruh Produk Terhadap Harga, menunjukan bahwa Produk berdasarkan uji hipotesis dengan tingkat signifikan $(\alpha)=5 \%$, diperoleh nilai $t_{\text {hitung }}$ $(4,652)>t_{\text {tabel }}(1,657)$. Hal ini berarti Produk berpengaruh signifikan positif terhadap Penjualan.

5. Pengaruh Harga Terhadap Bahan Baku, menunjukan bahwa Harga berpengaruh berdasarkan uji hipotesis dengan tingkat signifikan $(\alpha)=5 \%$, diperoleh nilai $t_{\text {hitung }}(3.603)>t_{\text {tabel }}(1,657)$. Hal ini berarti Harga berpengaruh signifikan positif terhadap Bahan Baku.

6. Pengaruh Produk Terhadap Bahan Baku, menunjukan bahwa Produk berpengaruh berdasarkan uji hipotesis dengan tingkat signifikan $(\alpha)=5 \%$, diperoleh nilai $t_{\text {hitung }}(1,945)>t_{\text {tabel }}(1,657)$. Hal ini berarti Produk berpengaruh signifikan positif terhadap Bahan Baku.

7. Pengaruh Produk, Harga, dan Bahan Baku terhadap Penjualan, berdasarkan hasil uji hipotesis diperoleh dengan menunjukan bahwa $\mathrm{f}_{\text {hitung }}(96,69)>$ $\mathrm{f}_{\text {tabel }}(2,29)$ maka $\mathrm{H}_{\mathrm{o}}$ ditolak. Dengan demikian dapat disimpulkan bahwa Produk, Harga, dan Bahan Baku berpengaruh simultan terhadap Penjualan

\section{SIMPULAN DAN SARAN}

Hasil penelitian secara ringkas dapat dijabarkan sebagai berikut; Dari uji korelasi antar variabel bebas menyatakan bahwa besaran nilai koefisien korelasinya berada pada tingkat cukup kuat, kuat, dan sangat kuat. Produk, Harga, dan Bahan Baku berpengaruh secara parsial signifikan dan positif terhadap penjualan di PT. Hon Chuan Indonesia. Oleh sebab itu ketiga variabel tersebut terbukti dapat meningkatkan penjualan di PT. Hon Chuan Indonesia. Produk, Harga, dan Bahan Baku secara simultan berpengaruh signifikan dan positif terhadap terhadap Penjualan di PT. Hon Chuan Indonesia. Karena itu ketiga variabel dependen terbukti dapat meningkatkan penjualan di PT.Hon Chuan Indonesia.

Bagi penelitian berikutnya, dapat melakukan penelitian lanjutan terkait pengaruh produk, harga, bahan baku terhadap penjualan dengan melakukan hal berikut ini: 1) melihat hasil pantauan atas kesesuaian dan perbaikan atas masing-masing variabel. 2) hendaknya melihat lebih dalam untuk variabel dengan nilai terendah dari hasil penelitian dengan memperpanjang periode penelitian meskipun hasil penelitian menunjukkan adanya korelasi 3) hendaknya melihat variabel lain yang memungkin memberikan pengaruh terhadap penjualan 4) perlunya dimasukkan faktor lain yang diduga akan mempengaruhi penjualan seperti kondisi politik dalam negeri. Penelitian ini juga belum mendalam karena belum melihat faktor kegiatan impor akan bahan baku yang memungkinkan adanya hambatan dalam menunjang hasil penjualan. Hal tersebut tentunya memerlukan lebih banyak waktu dan analisa lebih mendalam yang dilakukan secara langsung. Kendala pandemi covid-19 yang membatasi pertemuan secara langsung baik dengan sumber maupun dengan responden, memungkinkan adanya kelonggaran dalam memberikan informasi.

\section{DAFTAR PUSTAKA}

Cui, Bingqun., Yang, Kejia., dan Chou, Tingjui. (2016). Analyzing the Impact of Price Promotion Strategies on Manufacturer Sales Performance, Journal of Service Science and Management, 2016, 9, 182-187.

Dewi, Maya Widyana, dan Muryati, (2017). An Analysis of Production Cost Effect With Order Price Method on Sales Pricing of Products at PT. Aneka Printing Indonesia in Sukoharjo, International Journal of Economics, Business and Accounting Research (IJEBAR).

Ferreira, Zonia Dos Reis. (2019). Analysis of Business Marketing Strategy in an Effort to Increase the Sales Volume of Company X in Dili City, East Timor, European Journal of Business and Management.

Kelemu, Nigist., dan Mandefro, Gedam. (2017). The Role of Marketing Strategy for Sales Volume: A Case Study on Ethiopian Textile Firms, Ethiopia, Journal of Marketing and Consumer Research.

Kotler, Philip. dan Keller, Kevin Lane. 2016. Manajemen Pemasaran, Edisi 13, Jilid 1. Jakarta: Penerbit Erlangga.

Kotler, Philip. dan Keller, Kevin Lane. 2009. Manajemen Pemasaran, Edisi 13, Jilid 2. Jakarta: Penerbit Erlangga.

Manap, H. Abdul. 2016. Revolusi Manajemen Pemasaran. Jakarta: Mitra Wacana Media.

Oktaviyanti, Dwi., Masyhuri., dan Mulyo, Jangkung Handoyo. (2015). Analisis Bauran Pemasaran dan Performa Penjualan Produk "Industri Hilir Teh Walini”, Jurnal Agro Ekonomi Vol.26/No. 2. 
Priatna, Husaeri Priatna, dan Trisnawan, Mochamad Rudi. (2016). Pengaruh Persediaan Bahan Baku Dan Volume Penjualan Terhadap Laba Bersih Perusahaan (Studi Kasus Pada CV. Cisatex Di Daerah Majalaya), Jurnal Ilmiah Akuntansi Volume 7, Nomor 3.

Suartaman, I Komang. dan Purbadharmaja, I B. (2017). Pengaruh Modal dan Bahan Baku Terhadap Pendapatan Melalui Produksi Pengrajin Patung Kayu Di Kecamatan Sukawati Kabupaten Gianyar, Jurnal Fakultas Ekonomi dan Bisnis Universitas Udayana, Bali, Indonesia.

Sugiyono. 2017. Metode Penelitian Kuantatif, Kualitatif, dan R\&D. Bandung: Penerbit Alfabeta.

Sujarweni, V.Wiratna. 2018. Metodologi Penelitian Bisnis dan Ekonomi Pendekatan Kuantitatif. Yogyakarta: Penerbit Pustaka Baru Press.

Usuli, Sudarto. (2011). Pengaruh Persediaan Terhadap Volume Penjualan Suku Cadang Pada Cv. Metro Jaya Mandiri Poso, Jurnal EKOMEN Vol. 11 No. 2. 